\title{
Effects of vasodilating agents on cochlear blood flow in mice
}

\author{
Tsutomu Nakashima ${ }^{\text {a.b }}$, Alfred L. Nuttall a, Josef M. Miller ${ }^{\text {a, } *}$ \\ "Kresge Hearing Research Institute, The Unicersity of Michigan, 1301 East Ann Street, Ann Arbor MI48109-0506. USA \\ ${ }^{\mathrm{h}}$ Department of Otorhinolaryngology, Nagoya Unirersity School of Medicine, Nagoya, Japan
}

Received 13 November 1993; revised 13 July 1994; accepted 3 August 1994

\begin{abstract}
The mouse has several distinct advantages as an experimental model for study of the cochlear blood flow (CBF) in the mammal, particularly for studies involving genetic manipulation, development and aging factors. In this investigation we evaluated the effects of selected vasodilating agents on CBF using laser-Doppler flowmetry. Sodium nitroprusside. hydralazine and pentoxifylline were applied topically on the round window (RW) or systemically by a subcutaneous injection. Topical application of sodium nitroprusside and hydralazine elevated CBF significantly, while systemic administrations of these two drugs failed to elevate CBF consistently. Pentoxifylline did not change CBF following topical application but increased CBF slightly following systemic administration. Age and gender did not influence the CBF response to topical application of sodium nitroprusside.
\end{abstract}

Keywords: Laser-Doppler flowmetry; Sodium nitroprusside; Hydralazine; Pentoxifylline

\section{Introduction}

The mouse has several distinct advantages as an experimental model for human auditory function. Various genetic mouse models exist for conditions resembling human auditory disorders. Moreover, the mouse is a suitable animal for studies of the effects of aging on hearing, because life span of the mouse is relatively short and the form of sensorineural and vascular pathology mimics that found frequently in humans (Paigen et al., 1987; Li, 1992). In the past 25 years, over 700 published articles have described various aspects of the auditory system of the mouse (Henry and McGinn, 1992). However, few reports have described cochlear blood flow (CBF) in mice, probably because of the small size of the cochlea and the unavailability of appropriate measurement technology until relatively recently. In this study CBF was measured using laserDoppler flowmetry in mice and the effect of aging on CBF response to systemically and topically applied vasodilating agents was investigated.

\footnotetext{
${ }^{*}$ Corresponding author. Fax (313) 764-0014.
}

\section{Materials and methods}

The subjects for this investigation included thirtynine 2-month-old CBA mice (10 female, 29 male). three 10-month-old CBA mice (all male) and three 18-month-old CBA mice (all male). 2-month-old CBA mice were obtained from Jackson laboratories and the aged mice were obtained from National Institute of Aging. The animals were anesthetized with subcutaneous Ketamine $(100 \mathrm{mg} / \mathrm{kg})$ and Rompun $(10 \mathrm{mg} / \mathrm{kg}$ ), which was supplemented every $30 \mathrm{~min}$ with Ketamine $(50 \mathrm{mg} / \mathrm{kg})$. Core body temperature, measured with a rectal probe, was maintained at $37 \pm 1^{\circ} \mathrm{C}$ with a thermoregulated heating blanket.

Blood pressure (BP) in 21 of the mice was measured indirectly from the tail with the aid of a hydraulic occluder (Vascular Occluder, In Vivo Metric, CA) positioned close to the body. The vascular occluder had a $5 \mathrm{~mm}$ lumen diameter and $7 \mathrm{~mm}$ width. Water injected into the cuff tubing occluded the tail artery, while tail blood flow was measured by laser-Doppler flowmeter (TSI Laser Flo or Perimed Periflux). After the cuff pressure was increased sufficiently to occlude all distal flow in the tail, systolic BP was measured by deflating 
the cuff until blood flow began to return. BP was measured at several minute intervals in all except one of the animals in which vasodilating agents were administered subcutaneously, and in the 6 animals that received topical application of the drugs. In one animal, the relationship between systolic BP measured by the tail cuff method and mean BP measured directly via a cannula (PE10) inserted into the left femoral artery was determined while BP was altered by subcutaneous injection of phenylephrin and hydralazine. In two animals, left carotid BP was measured directly through a cannula (PE10).

The right tympanic bulla of each animal was opened via a ventral approach. After gently removing the middle ear mucosa from the surface of the cochlea, a laser-Doppler probe was placed over the lateral wall of the cochlea to measure CBF. The diameter of the probe was $0.4 \mathrm{~mm}$ (Perimed PF2) or $0.8 \mathrm{~mm}$ (TSI Laser Flo). The smaller diameter probe was used in 12 of 27 animals in which vasodilating agents were administered topically. Although the smaller probe gives a CBF reading from a smaller measurement volume, the perm centage change in flow for a drug stimulus was not altered by the probe size. A light petroleum gel was used to maintain a good optical coupling between the probe and the cochlea. The gel prevented fluid accumulation and extraneous red cells from moving under the probe. All recordings were done under stable illumination from the operating microscope.

Three vasodilating agents were investigated: sodium nitroprusside, hydralazine and pentoxifylline were applied topically or subcutaneously. Sodium nitroprusside and hydralazine are powerful vasodilators that increase nitric oxide (NO) which has recently been identified as an endothelium-derived relaxing factor (Ignarro, 1989). Sodium nitroprusside acts on the smooth muscle of both arterioles and venules, while hydralazine is a pure arteriolar dilator (Shepherd and Irvine, 1986). Pentoxifylline has a small vasodilator effect (Kaapa et al, 1991; Sonkin et al., 1992), although the most important function of pentoxifylline for improving blood flow is the result of an increase in red blood cell flexibility. To administer the vasodilating agents topically, 0.4 to 2.0 $\mu \mathrm{l}$ quantities of agents diluted in saline were applied to the round window ( $\mathrm{RW}$ ) niche by a microsyringe. Dose-response functions were determined on the basis of total drug weight applied to the RW (concentration of the drug times volume of the solution).

Sodium nitroprusside was applied topically in fourteen 2-month-old mice ( 12 males and 2 females), two 10-month-old mice and two 18-month-old mice. The concentration of sodium nitroprusside applied topically was $0.015-3.0 \%$. In some cases of topical application of sodium nitroprusside, it was dissolved in distilled water to lower the osmolarity. Osmolarity of $3 \%$ sodium nitroprusside dissolved in saline and distilled water was
$534 \mathrm{mOsm}$ and $273 \mathrm{mOsm}$, respectively. Acidity of $3 \%$ sodium nitroprusside was $\mathrm{pH} 5.1-5.2$ in either solution. For systemic administration of sodium nitroprusside, $0.2 \mathrm{mg} / \mathrm{kg}$ or $2 \mathrm{mg} / \mathrm{kg}$ was injected subcutaneously in six 2-month-old mice (all males), one 10-month-old mouse and one 18 month-old mouse.

For topical application of hydralazine, nine 2month-old mice (6 males and 3 females) were used. The concentration of hydralazine applied topically was $0.02-4.0 \%$. Two percent hydralazine dissolved in saline was $384 \mathrm{mOsm}$ and $\mathrm{pH} \mathrm{3.9}$. For systemic administration of hydralazine, $0.2 \mathrm{mg} / \mathrm{kg}$ or $2 \mathrm{mg} / \mathrm{kg}$ was injected subcutaneously in five 2 -month-old mice ( 3 males and 2 females).

For application of pentoxifylline, $5 \%$ pentoxifylline was applied topically in three 2-month-old mice (2 females and one male). Because $\mathrm{CBF}$ did not change following the topical application, subsequent injection of $50 \mathrm{mg} / \mathrm{kg}$ or $100 \mathrm{mg} / \mathrm{kg}$ pentoxifylline was performed subcutaneously. In one female 2-month-old mouse, $50 \mathrm{mg} / \mathrm{kg}$ pentoxifylline was injected subcutancously without prior topical application of pentoxifylline.

Changes in $\mathrm{CBF}$ are expressed as relative change in blood flow from an initial baseline. The value of the baseline level of CBF before the administration of the drug was considered as $100 \%$, and percentage change in CBF was plotted following the administration.

\section{Results}

Systolic BP measured by the cuff method correlated well with mean BP measured directly through a can-

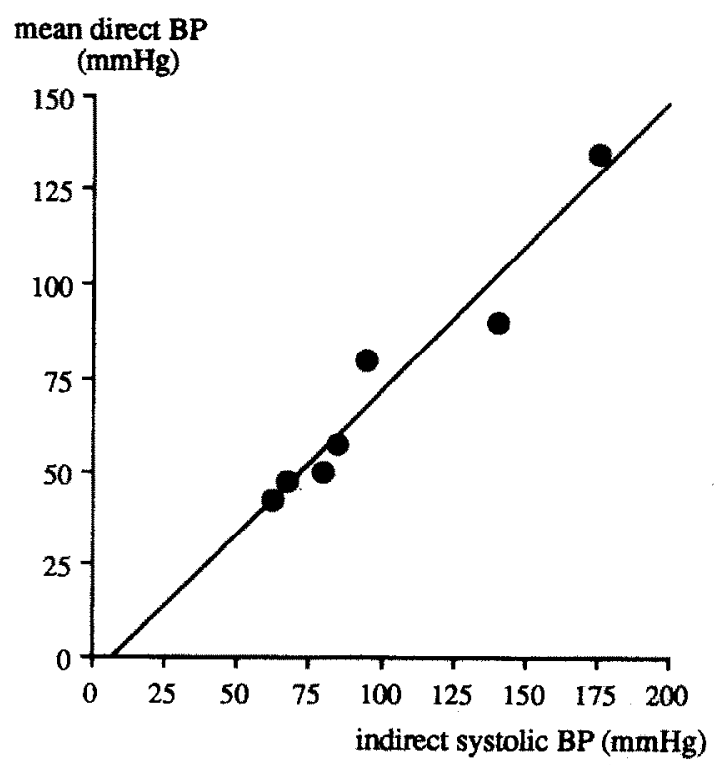

Fig. 1. Relationship between mean blood pressure (BP) measured directly in the femoral artery and systolic BP measured via the tail cuff method. 


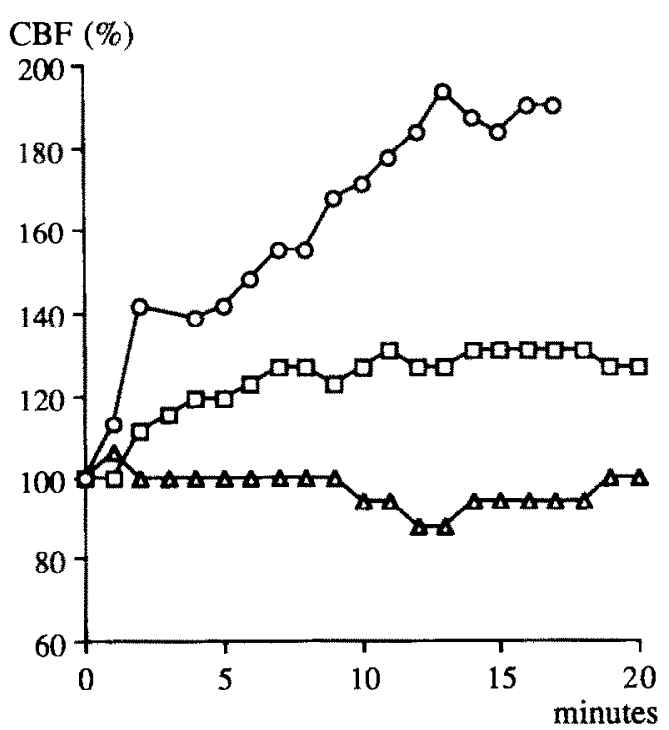

Fig. 2. Effects of topical application of sodium nitroprusside on cochlear blood flow (CBF). Various amounts of sodium nitroprusside were applied to the round window (RW) at time 0 . (Three representative examples: circle: $45 \mathrm{mg}$, square: $18 \mathrm{mg}$, triangle: $1.2 \mathrm{mg}$ ).

nula inserted into a femoral artery (Fig. 1). The correlation coefficient of the linear regression was 0.94 . The mean femoral BP was approximately $30 \%$ lower than the systolic BP measured via the tail cuff. BP measured by the cuff method immediately before drugs were applied was $116.3 \pm 31.8 \mathrm{mmHg}$ in young mice $(2$ month-old, $N=16$ ) and $116.5 \pm 13.4 \mathrm{mmHg}$ in the aged mice (10- or 18-month-old, $N=4$ ).

Sodium nitroprusside applied to the RW niche elevated $\mathrm{CBF}$ in a dose dependent manner. Fig. 2 is a representative example, showing that one minute following topical application of a moderate and high dose of sodium nitroprusside, CBF began to increase and reached a maximum level within about $10-15 \mathrm{~min}$. Because anesthesia time was restricted in mice (about 2 hours), it was not possible to observe $\mathrm{CBF}$ for a long time. However, there was no obvious recovery from these topically induced increases during the entire duration of the experiment. Fig. 3 shows the dose-response CBF function obtained for topically applied sodium nitroprusside in 18 animals. There was no significant change in response to topical sodium nitroprusside between young and aged micc. There was also no significant change in response between male and female mice. No difference in response was observed dependent on the vehicle used (saline or distilled water). In six animals, BP was measured before and after sodium nitroprusside was applied topically. No consistent change of $\mathrm{BP}$ was observed.

Fig. 4 shows the effect on CBF and BP of $2 \mathrm{mg} / \mathrm{kg}$ sodium nitroprusside injected subcutaneously. CBF showed a delayed, gradual change that saturated at a $20-60 \%$ increase $10-20 \mathrm{~min}$ following injection. When

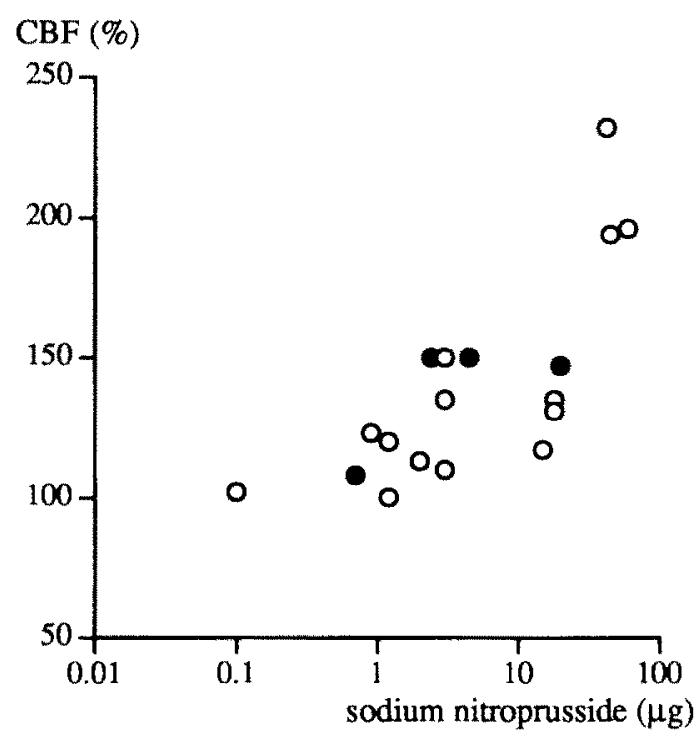

Fig. 3. Dose-response curve for $\mathrm{CBF}$ response with topically applied sodium nitroprusside. Open circles show fourteen 2 -month-old mice and filled circles show four aged mice. $100 \%$ of $\mathrm{CBF}$ indicates the baseline level before the application.

mean and standard deviation of CBF in four animals were calculated for one minute intervals, a statistically significant increase occurred between 3 and $22 \mathrm{~min}$ after the injection $(t$-test, $P<0.05)$. By contrast, BP decreased $15-35 \%$ in $2-10 \mathrm{~min}$ following injection. Both tend toward recovery. With $0.2 \mathrm{mg} / \mathrm{kg}$ sodium nitroprusside, BP still showed a $15-35 \%$ decrease but the increase in CBF was under about $10-20 \%$ (Fig. 5). These data indicate that the sodium nitroprusside effect on peripheral vessels is relatively saturated at these doses (i.e., similar BP decreases) while the dila-

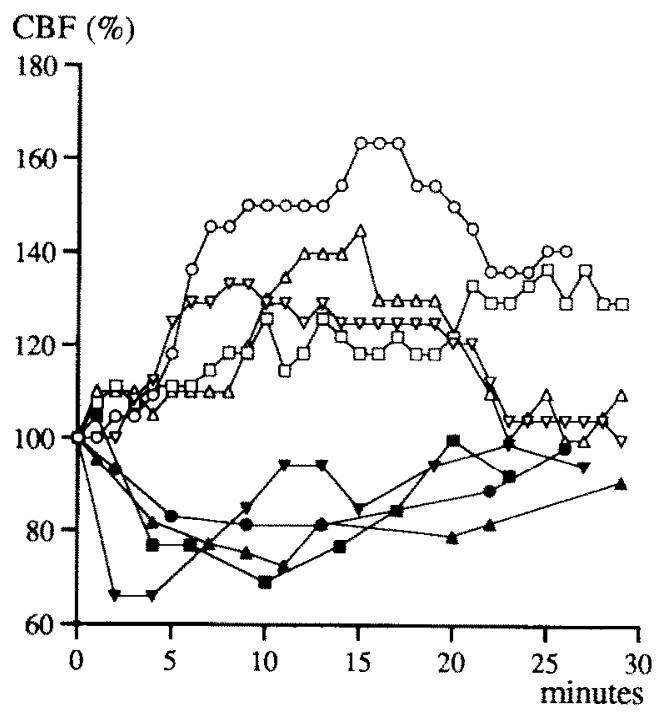

Fig. 4. Effect of $2 \mathrm{mg} / \mathrm{kg}$ subcutaneous sodium nitroprusside on $\mathrm{CBF}$ and BP. Open symbols mean CBF and closed symbols mean BP. The symbols represent four animals. 


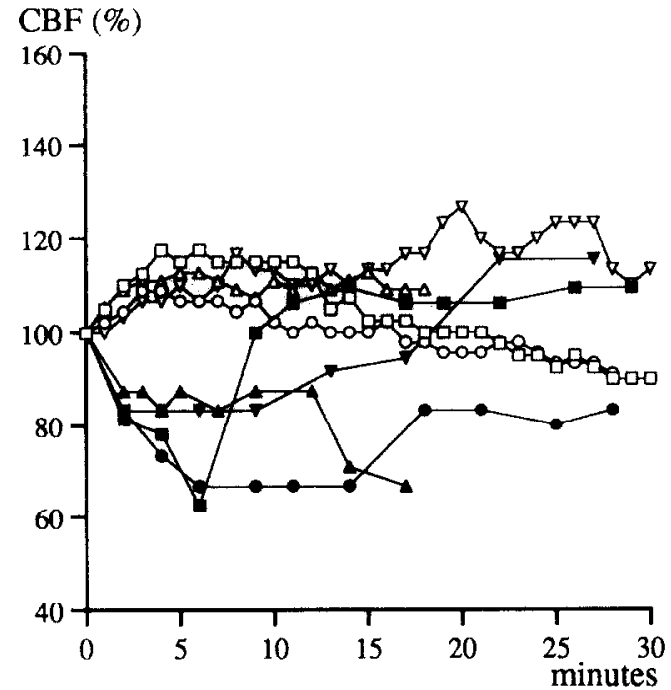

Fig. 5. Effect of $0.2 \mathrm{mg} / \mathrm{kg}$ subcutaneous sodium nitroprusside on $\mathrm{CBF}$ and BP. Open symbols mean $\mathrm{CBF}$ and closed symbols mean $B P$. The symbols represent four animals.

tion of cochlear vessels is not. One 18-month-old mouse died $20 \mathrm{~min}$ after subcutaneous injection of $0.2 \mathrm{mg} / \mathrm{kg}$ sodium nitroprusside.

Hydralazine applied to the RW niche also increased CBF in a dose dependent manner. CBF began to increase 2 or $3 \mathrm{~min}$ after the application of hydralazine, and reached a maximum level within $10 \mathrm{~min}$. Generally speaking, the CBF changes caused by topically applied hydralazine were similar to those of sodium nitroprusside. However, in two cases that showed an increase in CBF of less than $40 \%$ following application of the drug, CBF began to return toward the baseline within 30 min following the peak response

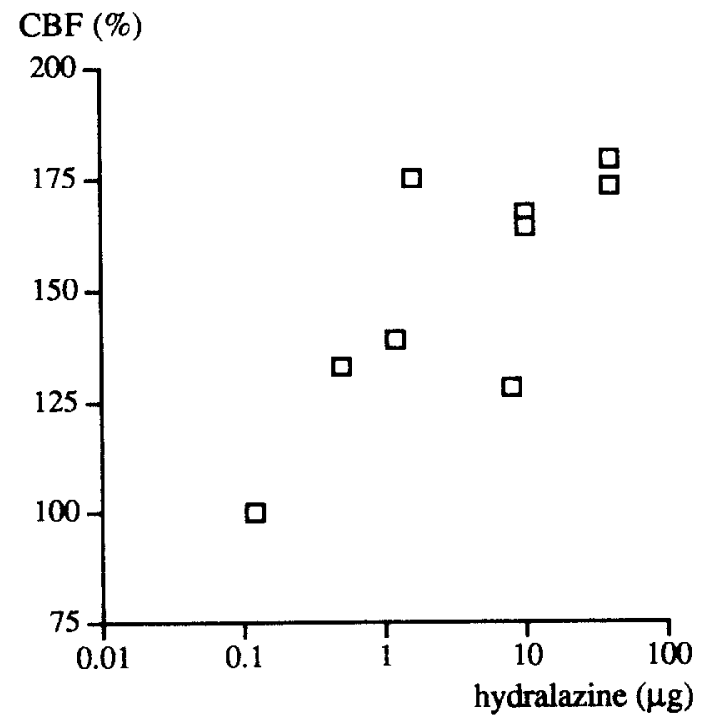

Fig. 6. Dose response curve for CBF response with topically applied hydralazine (nine 2-month-old mice).

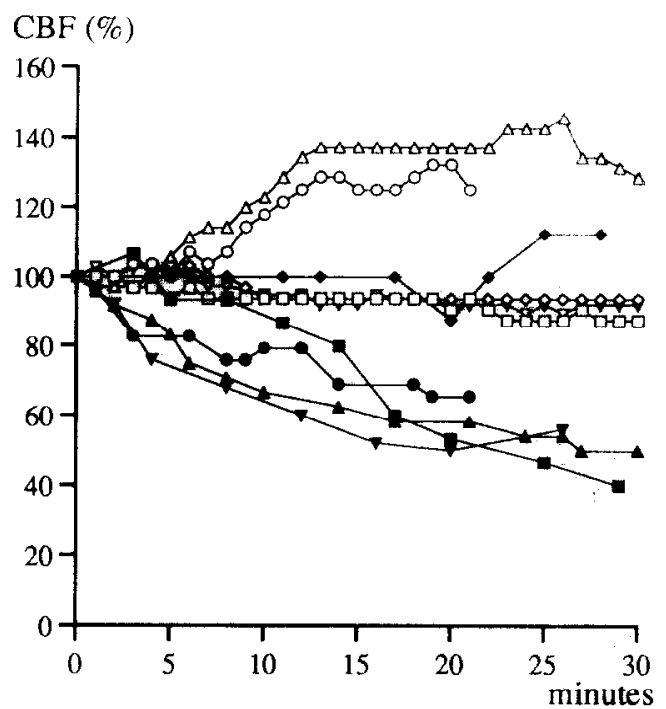

Fig. 7. Effect of $0.2 \mathrm{mg} / \mathrm{kg}$ or $2 \mathrm{mg} / \mathrm{kg}$ subcutaneous hydralazine on CBF and BP. Open symbols mean CBF and closed symbols mean $B P$. Two animals shown by triangles received $2 \mathrm{mg} / \mathrm{kg}$ and the other three animals received $0.2 \mathrm{mg} / \mathrm{kg}$.

level. The relationship between the total weight of hydralazine applied topically and the maximum response observed in CBF is shown in Fig. 6. There was no significant difference in response between males and females. We also did not find any difference in the response to topical application of sodium nitroprusside based on the diameter of probe $(0.4 \mathrm{~mm}$ or $0.8 \mathrm{~mm})$.

The effect of subcutaneously injected hydralazine $(0.2 \mathrm{mg} / \mathrm{kg}$ or $2 \mathrm{mg} / \mathrm{kg})$ on CBF is shown in Fig. 7 . Following subcutaneous injection of hydralazine, $\mathrm{BP}$ decreased in all except one animal in which $0.2 \mathrm{mg} / \mathrm{kg}$

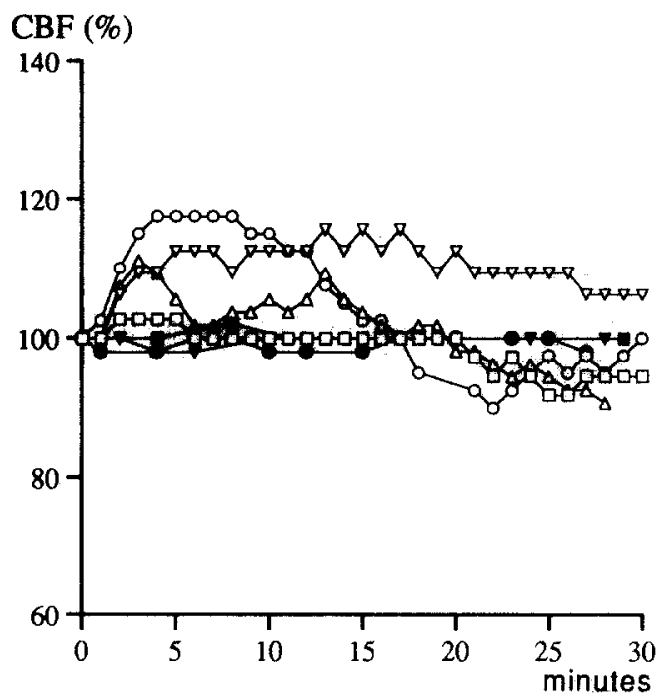

Fig. 8. Effect of $50 \mathrm{mg} / \mathrm{kg}$ or $100 \mathrm{mg} / \mathrm{kg}$ pentoxifylline on $\mathrm{CBF}$ and BP. Open symbols mean CBF and closed symbols mean BP. Two animals, shown by triangles, received $100 \mathrm{mg} / \mathrm{kg}$. 
hydralazine was injected. An increase in $\mathrm{CBF}$ was observed in 1 of 3 animals administered $0.2 \mathrm{mg} / \mathrm{kg}$ hydralazine and in 1 of 2 animals receiving $2 \mathrm{mg} / \mathrm{kg}$ hydralazine. In the 2 animals in which CBF increased following subcutaneous injection of hydralazine, $\mathrm{BP}$ was measured directly through a cannula inserted into the carotid artery.

Pentoxifylline did not increase CBF when $30-50 \mathrm{mg}$ was applied topically to the RW niche in 3 animals. When pentoxifylline was injected subcutaneously $(50$ $\mathrm{mg} / \mathrm{kg}$ or $100 \mathrm{mg} / \mathrm{kg}$ ), CBF increased by $10-20 \%$ within approximately $5 \mathrm{~min}$ in 3 of 4 animals without significant change of BP (Fig. 8). This CBF increase appeared to recover to baseline within $20 \mathrm{~min}$ of the subcutaneous injection ( 3 of 4 animals).

\section{Discussion}

It was possible to measure CBF in the mouse using laser-Doppler flowmetry. It thus appears that the status of $\mathrm{CBF}$ in various genetic mouse models of sensorineural hearing loss can be studied to investigate the role of CBF disturbance in inner ear deafness. The other advantage of the mouse rests with the availability of aged mice to study the relationship of CBF and functional changes in the inner ear with aging. Disadvantages of mice in the investigation of $\mathrm{CBF}$ are difficulty with cannulation of arteries or veins for $\mathrm{BP}$ measurement or drug administration, and difficulties with maintaining this small animal in a good physiological state for extended periods under anesthesia. This is gencrally due to respiratory deterioration.

To reduce the experiment time in the current study, a cuff method for measurement of BP of the tail artery was used in these studies. The cuff method has been widely used in many strains of young and aged mice for measurement of BP (Schlager, 1966; Weibust and Schlager, 1968). These studies showed that age related changes in BP may be quite different from strain to strain. In the CBA strain of mice, no increase of BP was observed with age after maturation (Henry et al., 1965). In the current study using CBA strain, the average BP was not different between young and aged mice.

We investigated the effect of 3 vasodilating agents: sodium nitroprusside, hydralazine and pentoxifylline on $\mathrm{CBF}$ in mice. Sodium nitroprusside and hydralazine, as powerful vasodilators, are used to lower severe hypertension. Sodium nitroprusside demonstrated a more pronounced effect on $\mathrm{BP}$ than $\mathrm{CBF}$. This may be related to the generally powerful effect of nitric oxide as a vasodilator. Considering the facts that the amount of sodium nitroprusside required to increase $\mathrm{CBF}$ in mice exceeds clinical dosage per body weight and that the clinical dosage of sodium nitroprusside typically used does not increase cerebral blood flow (Tinker and Michenfelder, 1976; Ivankovich et al.. 1976), it is possible that systemic administration of sodium nitroprusside would not increase CBF to a clinically useful degree.

Hydralazine did not increase CBF except in two cases. It is not clear why this was so. The effect of hydralazine on CBF has been studied earlier by Snow and Suga (1973) using impedance plethysmography in guinea pigs. They reported an increase of CBF with a drop in BP following intravenous injection of hydralazine. Miller et al. (1986) and Ohlsen et al. (1992), however, reported no increase in CBF using laser-Doppler flowmetry in guinea pigs, combined with a decrease in BP following systemic administration of hydralazine. This must mean that some cochlear vasodilation occurred to counteract the decreased systemic BP. Overall, the influence of systemically administered valsodilating agents on CBF is complicated by the dilatation of blood vessels in the whole body and the concomitant hypotension.

Subcutaneous administration of pentoxifylline increased CBF, a finding in agreement with previous observations (LaRouere et al., 1990): Coleman et al., 1990). This increase in CBF may reflect the rheological changes induced by pentoxifylline on blood viscosity and plasticity of red blood cells (Smith et al., 1986; De Felice et al., 1990; Mollitt and Poulos, 1991).

Topical application of vasodilating agents is an effective method to dramatically increase CBF. If the molecular weight of the drug is below 50)( the drug can pass through the round window membrane (Juhn et al., 1987). Three kinds of drugs we used have molecular weight less than 300. Ohlsen et al. (1992) observed significant increases in CBF following application of sodium nitroprusside or hydralazine to the RW in guinea pigs. We confirmed these strong effects of topical application of these drugs on CBF in the mouse. Obviously toxic effects of these drugs must be studied in order to evaluate clinical usefulness (Ohlsen et al., 1993). Topical application of pentoxifylline was tried in the present study without significant effect on CBF. This is consistent with its primary effect on red cells.

Our study did not show significant difference in response of CBF to topically applied sodium nitroprusside between young and aged mice. However, the oldest mice were only 18 months of age. This result is consistent with previous reports that investigated the effect of aging on response of blood vessels to topical sodium nitroprusside in other vascular systems, c.g. the basilar artery (Hatake et al., 1990) or the brachial artery (Imaizumi et al., 1990). However, with systemic administration of sodium nitroprusside, elderly subjects demonstrated an increased sensitivity (Irvine and Shepherd, 1984; Minaker et al.. 1991), presumably in part because baroreflex function decreased with age. 
Effects of aging on CBF are important in relation to presbycusis (Johnsson and Hawkins, 1976; Gates et al., 1993). Prazma et al. (1990) reported that CBF decreased in 2- to 3-year old gerbils. Hillerdal et al. (1987), however, observed that CBF in 8- to 24-monthold normotensive rats was not significantly different from that found in 3-to 6-month-old normotensive rats.

The effect of age on CBF may be different in each animal according to its life span. Because life span of the mouse is short (about two years) and many aging studies have been performed in mice, we suggest that the mouse is a useful model to extend our knowledge of the basis for and the role of CBF in age related hearing changes of presbycusis.

\section{Acknowledgements}

We would like to acknowledge J. Nadine Brown and Gary A. Dootz for their technical assistance in performing this experiment. We also wish to thank Professor Noriyuki Yanagita, Nagoya University School of Medicine, Nagoya, Japan for his support of this study. Supported by NIH Grants DC00105 and AG08885.

\section{References}

Coleman, J.K, Quirk W.S., Dengerink, H.A. and Wright J.W. (1990) Pentoxyphylline increases cochlear blood flow while decreasing blood pressure in guinea pigs. Hear. Res. 47, 169-174.

DeFelice, M., Gallo, P. and Masotti, G. (1990) Current therapy of peripheral obstructive arterial disease. Angiology 41, 1-11.

Gates, G.A., Cobb, J.L., D'Agostino, R.B. and Wolf, P.A. (1993) The relation of hearing in the elderly to the presence of cardiovascular disease and cardiovascular risk factors. Arch. Otolaryngol. Head Neck Surg. 119, 156-161.

Hatake, K., Kakishita, E., Wakabayashi, I., Sakiyama, N. and Hishida, S. (1990) Effect of aging on endothelium-dependent vascular relaxation of isolated human basilar artery to thrombin and bradykinin. Stroke 21, 1039-1043.

Henry, J.P., Meehan, J.P., Stephens, P. and Santisteban, G.A. (1965) Arterial pressure in CBA mice as related to age. J. Gerontol. 20, 239-243.

Henry, K.R. and McGinn, M.D. (1992) The mouse as a model for human audition. A review of the literaturc. Audiology 31, 181189.

Hillerdal, M., Borg, E., Engstrom, B. and Hultcrantz, E. (1987) Cochlear blood flow in relation to age in normotensive and spontaneous hypertensive rats. Acta Otolaryngol. (Stockh.) 104, $243-250$.

Imaizumi, T., Takeshita, A., Suzuki, S., Yoshida, M., Ando, S. and Nakamura, M. (1990) Age-independent forearm vasodilatation by acetylcholine and adenosine 5 'triphosphate in humans. Clin. Sci. 78, 89-93.

Irvine, N.A. and Shepherd A.M.M. (1984) Age and blood pressure determine vasodepressor response to sodium nitroprusside. J. Cardiovasc. Pharmacol. 6, 816-821.
Ignarro, L.J. (1989) Endothelium-derived nitric oxıde: actions and properties. FASEB J. 3, 31-36.

Ivankovich, A D., Miletich, D.J., Albrecht, R.F. and Zahed, B. (1976) Sodium nitroprusside and cerebral blood flow in the anesthetized and unanesthetized goat. Anesthesiology 44, 2126.

Johnsson, L G. and Hawkins, J.E. Jr. (1976) Vascular changes in the human inner ear associated with aging. Ann. Otol. Rhinol. Laryngol. 81, 364-376.

Juhn, S.K, Hamaguchi, Y. and Goycoolea M. (1987) Review of round window membrane permeability. Acta Otolaryngol. (Stockh) Suppl. 457, 43-48.

LaRouere, M.J., Sillman, J.S., Tsai, M.J. Nuttall, A L. and Miller. J.M. (1990) The effect of pentoxifylline on cochlear blood flow. ARO

Kaapa, P., Raj, J.U. and Ibe, B.O. (1991) Effect of pentoxifylline in rabbit pulmonary circulation: influence of age and vasomotor tone. Am. J. Physiol. 261, H975-981.

Li, H.S. (1992) Genetic influences on susceptibility of the auditory system to aging and environmental factors. Scand. Audiol. Suppl. $361-39$.

Miller, J.M, Hultcrantz, E., Short, S., and Nuttall, A L. (1986) Pharmacological effects on cochlear blood flow measured with laser-Doppler technique. Scand. Audiol. (suppl) 26, 11-20.

Minaker, KL., Meneilly, G.S. Young, J.B., Landsberg, L., Stoff, J.S., Robertson, G.L. and Rowe, J.W. (1991) Blood pressure, pulse, and neurohumoral responses to nitroprusside-induced hypotension in normotensive aging men. J. Gerontol. 46, M151-154.

Mollitt, D.L., and Poulos, N.D. (1991) The role of pentoxifylline in endotoxin-induced alterations of red cell deformability and whole blood viscosity in the neonate. J. Pediatr. Surg. 26, 572-574.

Ohlsen, KA., Didier, A., Baldwin, D., Miller, J.M., Nuttall,A L. and Hultcrantz, E. (1992) Cochlear blood flow in response to dilating agents. Hear. Res. 58, 19-25.

Ohlsen, A., Hultcrantz, E. and Engstrom B. (1993) The effect of topical application of vasodilating agents on cochlear electrophysiology. Acta Otolaryngol. (Stockh.) 113, 55-61.

Paigen, B., Morrow, A., Holmes, P.A., Mitchell, D. and Williams, R.A. (1987) Quantitative assessment of atherosclerotic lesions in mice. Atherosclerosis 68, 231-240.

Prazma, J., Carrasco, V.N., Butler, B., Waters, G., Anderson, T. and Pillsbury, H.C. (1990) Cochlear microcirculation in young and old gerbils. Arch. Otolaryngol. Head Neck Surg. 116, 932936.

Schlager, G. (1966) Systolic blood pressure in eight inbred strains of mice. Nature 212, 519-520.

Smith, R.V., Waller, E.S., Dolvisio, J.T., Bauza, M.T., Puris, K., Ho, I. and Lassman, H.B. (1986) Pharmacokinetics of orally administered pentoxifylline in humans. J. Pharm. Sci. 75, 47-52.

Snow, J.B. and Suga, F. (1973) Labyrinthine vasodilators. Arch. Otolaryngol. $97,365-370$.

Shepherd, A.M. and Irvine, N.A. (1986) Differential hemodynamic and sympathoadrenal effects of sodium nitroprusside and hydralazine in hypertensive subjects. J. Cardiovasc. Pharmacol. 8 , $527-533$.

Sonkin, P.L., Chen, L.E., Seaber, A.V. and Hatchell, D.L. (1992) Vasodilator action of pentoxifylline on microcirculation of rat cremaster muscle. Angiology 43, 462-469.

Tinker, J.H. and Michenfelder, J.D. (1976) Sodium nitroprusside: Pharmacology, toxicology and therapeutics. Anesthesiology 45 . 340-354.

Weibust, R.S. and Schlager, G. (1968) A genetic study of blood pressure, hematocrit and plasma cholesterol in aged mice. Life Sci. 7, 1111-1119. 